\title{
AN ASSESSMENT OF GOLD AS A HEDGE OR SAFE HAVEN:
EVIDENCE FROM MAJOR GOLD PRODUCING COUNTRIES
}

\author{
Jambotkar \\ Mrunali Manohar ${ }^{1+}$ \\ iD Guntur Anjana \\ Raju $^{2}$
}

\author{
${ }^{\prime}$ Ph.D. Research Scholar, Goa Business School, Goa University, Goa, India. \\ Email:mrunalijambotkar@gmail.com Tel:7057121380 \\ ${ }^{2}$ Professor and Program Director of Ph.D. (Commerce), Goa Business \\ School, Goa University, Goa, India. \\ Email:anjana@unigoa.ac.in Tel:8390701433
}

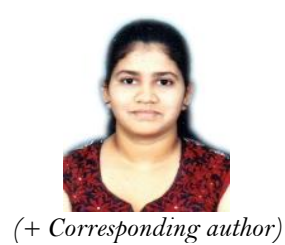

Article History

Received: 7 April 2021 Revised: 11 May 2021 Accepted: 2 June 2021 Published: 29 June 2021

\section{Keywords}

Safe haven

Hedge

Wavelet analysis

Diversification

Gold

Equity indices

Risk management.

JEL Classification: G01; G11; G15.

\section{ABSTRACT}

In the era of globalization, co-movement among the various financial assets has increased drastically and diversification benefits have reduced. Further, increased uncertainties in the financial system posed a serious challenge to researchers and investors in the search for alternative avenues for safeguarding their wealth and risk management. Therefore, using daily time series data that spans from January 2000 to March 2020, the study assesses the role of gold as a hedge and safe haven against equity market indices of major gold producing countries. The GARCH model, which covers average gold returns, highlighted the hedge and safe haven ability of gold in different quantiles of the return distribution. The results revealed that the severity of shock rarely matters in capturing the demand for safe haven assets. Additionally, a comparative analysis during crises evidenced a more heterogeneous and larger effect during the dot-com bubble burst in comparison with other selected crises. The robustness analysis through wavelet coherence with the predominance of red bounds and westward-facing arrows indicates the strong safe haven effect of gold during most of the crisis periods in the cases of Australia and South Africa. Furthermore, an improved understanding of such hedge and safe haven behavior patterns may have substantial implications for hedgers, portfolio managers, investors, and policy makers.

Contribution/Originality: This study uses the new estimation framework, i.e., wavelet analysis, to capture specific crisis effects which may differ across time and investment horizons. It also analyzes the attribute of gold as a risk management tool and its ability to shield investors during extreme market downturns.

\section{INTRODUCTION}

After the debacle of the Bretton Woods fixed regime system, gold no longer served as a basis of the International Monetary System. This led to the emergence of gold being treated on par with other commodities and its assessment as to whether it acts as an internal or external hedge. Furthermore, the financial markets are subject to turbulence. The recent global financial crisis (2007-2008) intensified with the collapse of the Lehman brothers and has caused uncertainty and shattered the investors' faith in the financial system. The beginning of the global financial crisis was marked by an impressive increase in gold prices, while other assets (stock prices in particular) exhibited losses. The dawn of numerous black swan events, such as the dot-com bubble burst, the global financial crisis, the European debt crisis and the ongoing Covid-19 crisis, have severely hampered the prices and caused instability in the global financial system. 
Owing to these increased financial uncertainties and risks within the financial system, there has been a quest to find a safe haven and hedge asset. The financial media often refers to gold as a safe haven asset for portfolio investors. Kaul \& Sapp (2006) defined a safe haven as "an ideal venue to park money during periods of uncertainty", while the first operational definitions of hedge and safe haven were propounded by Baur \& McDermott (2010). Accordingly, "a hedge (safe haven) is an asset that is uncorrelated (negatively correlated) with another asset or portfolio on average (only in times of market stress or turmoil)”.

In the era of globalization, co-movement among various instruments has increased drastically. The greatest difficulty exists in the context of portfolio management when analyzing the behavior of instruments, which doesn't depend on the behavior of other instruments and follows a completely different path. With the rising turbulence in financial markets, a need for hedge/safe haven assets emerged a decade ago and is gaining relevance and popularity. The beginning of the global financial crisis in 2008 has been marked with a renewed interest in understanding the properties of gold as an investment tool on account of its ability to limit losses in times of market turbulence. Furthermore, gold often exhibits a lack of correlation with other assets (Baur \& McDermott, 2010) and is considered as a zero-beta asset (McCown \& Zimmerman, 2006). In this vein, gold seems to be an appropriate asset to be considered as a hedge or a safe haven for financial portfolios. The reason is that, in contrast to many other commodities, gold is well-known to be durable, easily recognizable, storable, portable, divisible, and easily standardized.

Numerous existing studies have documented hedge and safe haven properties for stocks. For instance, Baur \& McDermott (2010) provided the first operational definition of hedge and safe haven. In their paper, they examine the static and time-varying relations between US, UK and German stock returns and gold returns and reported that gold is a safe haven for equities in the US, UK and Germany on average, but not for bonds in any of the markets. The definitional approach was further extended to define a strong hedge/safe haven and a weak hedge/safe haven by Baur \& McDermott (2010). The findings evidenced the major role of safe haven assets in the developed markets of Europe and the US but not in emerging BRICS markets (Brazil, Russia, India, China, and South Africa), Japan, Canada, and Australia. Hood \& Malik (2013) tested the ability of precious metals as well as volatility index in offering hedge and safe haven instrument against the stock market in the US. The findings imply that, unlike other precious metals, gold acts as a better hedge and weak safe haven instrument against the stock market in the US. In a nutshell, VIX offers a comparatively better hedge and safe haven ability than gold, especially during turbulent times. Similarly, Lucey \& Li (2015) supported the prominent role of precious metals in risk management during crisis periods. Gurgun \& Unalmıs (2014) carried out a study in emerging and developing countries by considering both domestic and international perspectives. From a domestic investor perspective, gold acts as a hedge and haven asset and these findings also hold in the post-global crisis periods. Through a broad set of 18 individual markets and five regional indices, Beckmann, Berger, \& Czudaj (2015) confirmed the market-specific ability of gold as a hedge and safe haven against stocks during two extreme regimes.

A separate strand of studies by Bhanja \& Dar (2015); Bredin, Conlon, \& Potì (2015); Dar \& Maitra (2017); Bekiros, Boubaker, and Uddin, \& Nguyen (2017) employed a wavelet coherence analysis to study hedge and safe haven potential at different times and investment horizons. Bredin et al. (2015) found that gold serves as a hedge and safe haven against traditional investment assets up to the horizon of one year. Diverse results across crises suggested safe haven ability during the Black Money crash in 1987 and global financial crises. But during the economic contradictions of 1980 positive coherence exists among assets. Additionally, Bhanja \& Dar (2015) examined the hedge and safe haven property of gold for multi-horizon stock market investors of three major gold consuming countries. The methodological approach of wavelet power and wavelet coherence was applied to test the hedge and safe haven properties for investors, and the wavelet coherence and cross wavelet phase angle was applied to assess the relationship between stock returns and returns in the gold market for both calm and turbulent periods. The results indicate that the two assets are not correlated on average and are mostly independent for calm and 
turbulent periods. Interestingly, Bekiros et al. (2017) considered the hedging and diversification role of gold by analyzing its interaction with the stock markets of the leading emerging economies, the BRICS. Using a multi-scale wavelet approach and a GARCH-based copula methodology, the results revealed the timescale evolvement patterns and a strong time-varying asymmetric dependence structure between BRICS stock markets and the gold market. These findings are essential for risk diversification and portfolio hedging strategies among the investigated markets.

Overall, the study contributes to the literature in several aspects by investigating the hedge and safe haven potential of gold for stocks markets of gold producing countries. On one side, the traditional Baur \& Lucey (2010) framework was adopted to understand safe haven potential at different quantiles as well as at different crisis periods. Furthermore, a robustness test through wavelet analysis confirmed richer characterization of hedge and safe haven abilities in both calendar time and frequency horizons. The safe haven property is dynamic and depends upon the nature of market turmoil, so the study examines the safe haven property of traditional yellow metal by comparing extreme events/crisis periods. Including the latest Covid-19 pandemic also provides additional insight.

The rest of the paper is organized into four key sections. Section 2 presents the data description; Section 3 outlines the detailed methodological framework employed to test the hedge and safe haven characteristics; Section 4 discusses the analysis and findings of the study; and Section 5 contains concluding remarks.

\section{DATA DESCRIPTION}

The sample data consist of daily observations of gold prices and stock market indices, both measured in terms of local currency, and were sourced from the World Gold Council (WGC) and the Bloomberg database, respectively. The sample countries (China, the United States of America (USA), Australia, Canada, and South Africa) are included in the study as they are among the major gold producing countries according to the World Gold Council classification. The sample period covers January $1^{\text {st }}, 2000$ to March $31^{\text {st }}$, 2020 and therefore encompasses four major turmoils, namely the dot-com bubble burst, the global financial crisis, the European debt crisis, and the Covid-19 crisis. As indicated by the contagion literature, it is not straightforward to determine the outset and the end of a crisis (Baur \& McDermott, 2010), so it is important to select the crises periods and define their start dates and the lengths. We defined March 1 $1^{\text {st }}, 2000$ to October $31^{\text {st }}, 2001$ for the dot-com bubble burst; August $1^{\text {st }}, 2007$ to March $31^{\text {st }}, 2009$ for the global financial crisis; January $1^{\text {st }}, 2010$ to December $31^{\text {st }}, 2011$ for the European debt crisis; and December $31^{\text {st }}, 2019$ to March 31 $1^{\text {st }}, 2020$ for the Covid-19 crisis. The returns for the stock prices and gold prices are estimated as $r(t)=\ln (\mathrm{P}(\mathrm{t}) / \mathrm{P}(\mathrm{t}-1))$, wherein $\mathrm{r}(\mathrm{t})$ stands for returns at time $t$, and $\mathrm{P}(\mathrm{t})$ and $\mathrm{P}(\mathrm{t}-1)$ stand for prices at times $\mathrm{t}$ and $\mathrm{t}-1$, respectively.

\section{RESEARCH METHODOLOGY}

This section presents the modelling framework, as adopted by Baur \& McDermott (2010), to examine the hedge and haven property of gold against the stock market. We assume that the dynamics between gold and stock is non-linear, especially during extreme market conditions. Specifically, the following models are estimated:

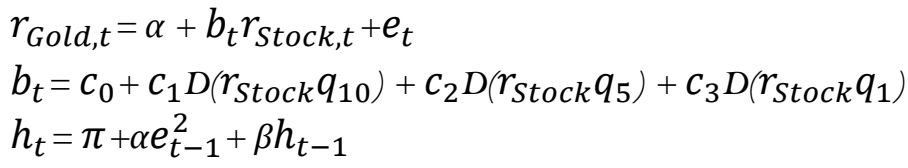

Equation (1a) depicts the relationship between the returns of gold and stock. In Equation (1b), $b_{t}$ is exhibited as a dynamic process by including dummies $\mathrm{D}(\ldots$.$) that capture the outcome of stress or extreme equity market$ movements. The times dummies $\mathrm{D}(\ldots$.$) assume the value equal to one if the stock market returns are in the$ predetermined lowest quantiles of return distribution, i.e., $10 \%, 5 \%$ and $1 \%$, respectively, and zero otherwise. If the parameters $\left(c_{1}, c_{2}, c_{3}\right.$ and $\left.c_{4}\right)$ specified in Equation $(1 \mathrm{~b})$ are negative, then gold serves as a weak safe haven. If the parameters are negative and statistically significant, then gold serves as a strong safe haven. If parameter $C_{0}$ is zero 
(negative), then gold acts as a weak (strong) hedge provided that the sum of parameters $C_{1}$ to $C_{4}$ are not jointly positive exceeding the value of $c_{0}$. In order to capture the heteroscedasticity problem in the data series, the GARCH(1,1) model is used and expressed through Equation (1c). All equations are calculated through the maximum likelihood estimation (MLE).

Finally, a less statistical and arbitrary approach would be to consider certain periods, such as major economic and financial crises explicitly (rather than the creation of thresholds), and to create time dummies equal to 1 if the returns overlap within the predefined phases of the crises, and zero otherwise. The following model is specified to check the ability of gold as a safe haven, specifically during crisis periods:

$r_{\text {Gold }, t}=\alpha+b_{t} r_{\text {Stock }, t}+e_{t}$

$b_{t}=c_{0}+c_{1} D($ Dot Com bubble burst $)+\ldots \ldots+c_{n} D($ Covid -19 crisis $)$

$h_{t}=\pi+\alpha e_{t-1}^{2}+\beta h_{t-1}$

Equation (2a) displays the principal regression equation between gold and stock returns. If the estimated coefficients of the equation, as expressed in Equation (2a) $\left(c_{1}, c_{2}, c_{3}\right.$ and $\left.c_{4}\right)$, are zero/negative and statistically significant, gold acts as a safe haven in the respective stress/crisis period. However, if the parameters are positive, gold is not a safe haven as it co-moves with the stock market (Baur \& McDermott, 2010; Chkili, 2016; Gurgun \& Unalmis, 2014). Equation (2c) indicates the results of the $\operatorname{GARCH}(1,1)$ model, which captures the problem of heteroscedasticity in the data series.

\subsection{Wavelet Coherence}

To analyze the localized correlation between two time series, a bivariate framework is essential. This can be measured through the cross wavelet spectrum between two time series, i.e., $p(t)$ and $q(t)$. The cross wavelet spectrum is the product of its wavelet coefficients and is expressed as:

$$
W_{\lambda, \mathrm{T}}(p, q)=W_{\lambda, \mathrm{T}}(p) W_{\lambda, \mathrm{T}^{*}(q)}
$$

Wherein, * indicates the complex conjugate. The limitation of the cross wavelet spectrum is that it is determined by the variance of each time series. To deal with this, most of the previous studies have applied wavelet coherence. With 'O' being a smoothing operator, wavelet coherence is calculated as:

$$
R_{\lambda, T}^{2}(p, q)=\frac{\left|O\left(\lambda^{-1} W_{\lambda, T}(p, q)\right)\right|^{2}}{O\left(\left|\left(\lambda^{-1} W_{\lambda, T}(p)\right)\right|^{2}\right) O\left(\left|\left(\lambda^{-1} W_{\lambda, T}(q)\right)\right|^{2}\right)}
$$

Wavelet coherence corresponds to squared correlation as it measures covariance between two time series divided by its variance at different times and scales. $R_{\lambda, \mathrm{T}}^{2}(p, q)$ implies that the wavelet coherence value lies between zero and one. The higher value indicates higher co-movement, while the lower value indicates lower comovement. The Monte Carlo Simulation method is then applied to determine statistical significance (Torrence \& Compo, 1998). The phased difference information is revealed through the arrows on the coherence plot. The phased difference between two time series is defined as:

$$
\emptyset_{\lambda, T}(p, q)=\tan ^{-1}\left(\frac{I\left\{o\left(\lambda^{-1} W_{\lambda, T}(p, q)\right)\right\}}{R\left\{o\left(\lambda^{-1} W_{\lambda, T}(p, q)\right)\right\}}\right)
$$

The I and R symbolize imaginary and real parts of wavelet coefficients, respectively. The phase is indicated by arrows, wherein the direction of arrows signifies positive and negative correlation among the time series. This confirms whether gold serves as a hedge or a safe haven at different times and frequency domains. 


\section{ANALYSIS AND INTEPRETATION}

Table 1. Summary statistics and correlation of gold returns and stock returns.

\begin{tabular}{|c|c|c|c|c|c|c|c|}
\hline Country & Series & Mean & SD & Skewness & Kurtosis & JB test & Correlation \\
\hline \multirow{2}{*}{ China } & Gold & 0.0295 & 1.0686 & -0.2489 & 9.1013 & 8245.71 **** & \multirow{2}{*}{0.0122} \\
\hline & Stock & 0.0132 & 2.8959 & -0.0235 & 1406.3690 & $4.33 \mathrm{E}+08$ *** & \\
\hline \multirow{2}{*}{ USA } & Gold & 0.0324 & 1.0731 & -0.2548 & 9.0351 & $8071.61^{* * *}$ & \multirow{2}{*}{-0.0128} \\
\hline & Stock & 0.0109 & 1.2492 & -0.3644 & 17.5861 & $46931.44^{*} * *$ & \\
\hline \multirow{2}{*}{ Australia } & Gold & 0.0092 & 1.0012 & -0.7852 & 12.3847 & 19922.30 *** & \multirow{2}{*}{-0.1231} \\
\hline & Stock & 0.0339 & 1.0974 & 0.4725 & 17.1797 & 44439.13 *** & \\
\hline \multirow{2}{*}{ Canada } & Gold & 0.0322 & 1.0568 & -0.1569 & 10.1372 & $11230.63^{* * *}$ & \\
\hline & Stock & 0.0088 & 1.1166 & -0.9809 & 20.9916 & $72074.23 * * *$ & -0.0127 \\
\hline \multirow{2}{*}{$\begin{array}{l}\text { South } \\
\text { Africa }\end{array}$} & Gold & 0.5271 & 1.2812 & 0.1934 & 7.9509 & 5426.47 *** & \\
\hline & Stock & 0.0316 & 1.1934 & -0.3776 & 8.6690 & 7197.04 **** & -0.0022 \\
\hline
\end{tabular}
significance at $1 \%, 5 \%$ and $10 \%$ levels, respectively.

Table 1 reports the summary statistics of daily stock market and gold returns. The average daily gold returns are highest (0.5271) in the case of South Africa and lowest in the case of Australia (0.0092). The Canadian stock market index offers negative returns, while the Australian stock market shows a maximum return of 0.0339. The standard deviations of all stock indices, as well as gold, are close to each other, except for China, which shows the higher quantum of risk in its stock market investment. The return distributions for the stock indices and gold are negatively skewed, except for the gold returns of South Africa and stock returns of Australia, which are positively skewed. A kurtosis coefficient above three and the Jarque-Bera test statistics show that the return series are not normally distributed. The null hypothesis of normality is rejected at the significance level of $1 \%$. Correlation analysis is a qualitative approach to evaluate the degree of association between the variables. The correlation coefficient between gold and stock indices of all countries, with the exception of China, is noted to be negative. Furthermore, there is a low degree of association among gold and stock indices of all the selected countries.

Table 2. Testing for stationarity, ARCH effects, and autocorrelation.

\begin{tabular}{|c|c|c|c|c|c|}
\hline \multirow[t]{2}{*}{ Country } & \multirow[t]{2}{*}{ Series } & \multicolumn{2}{|c|}{ ADF Unit Root Test } & \multirow[t]{2}{*}{ ARCH LM Test } & \multirow[t]{2}{*}{ LB Q Statistics } \\
\hline & & With Intercept & $\begin{array}{c}\text { With Intercept } \\
\text { and Trend }\end{array}$ & & \\
\hline \multirow[t]{2}{*}{ China } & Gold & $-73.9502^{* * *} *$ & $-73.9462 * * *$ & $358.5516^{* * * *}$ & $26.736^{* * * *}$ \\
\hline & Stock & $-25.8563 * * *$ & $-25.8572 * * *$ & $1753.477^{* * * *}$ & $689.50^{* * * *}$ \\
\hline \multirow[t]{2}{*}{ USA } & Gold & $-73.3424 * * *$ & $-73.3438 * * *$ & $370.3623^{* * *} *$ & $27.026^{* * * *}$ \\
\hline & Stock & $-82.5537 * * *$ & $-82.5615^{* * *}$ & $707.1854^{* * * *}$ & $87.113 * * *$ \\
\hline \multirow[t]{2}{*}{ Australia } & Gold & $-76.7806^{* * *}$ & $-76.7808^{* * *}$ & $606.9994^{* * *}$ & $16.303^{* * *}$ \\
\hline & Stock & $-76.5009^{* * * *}$ & $-76.4937 * * *$ & 1338.411 **** & $73.899 * * *$ \\
\hline \multirow[t]{2}{*}{ Canada } & Gold & $-76.3463 * * *$ & $-76.3390 * * *$ & $458.6951^{* * * *}$ & $61.086^{* * * *}$ \\
\hline & Stock & $-27.6566^{* * * *}$ & $-27.6578^{* * *}$ & 1398.057 *** & $64.198 * * *$ \\
\hline \multirow[t]{2}{*}{ South Africa } & Gold & $-73.9873^{* * *}$ & $-73.9804^{* * * *}$ & $683.5184^{* * * *}$ & $25.559^{* * *}$ \\
\hline & Stock & $-70.5133^{* * *} *$ & $-70.5226^{* * *}$ & $1238.083^{* * * *}$ & $42.815^{* * *}$ \\
\hline
\end{tabular}

Note: ADF unit root test is the empirical statistic to determine stationary; ARCH-LM test indicates the Lagrange multiplier test for conditional heteroscedasticity up to 20 lags and the Ljung-Box Q-Statistic is a test for serial correlation up to 20 lags; ***, **, * denote rejection of the null hypothesis of unit root, no $\mathrm{ARCH}$ effects, and no autocorrelation at the $1 \%, 5 \%$ and $10 \%$ levels of significance, respectively.

Table 2 summarizes the results of the augmented Dickey-Fuller (ADF) unit root test. The null hypothesis of ADF is rejected, which indicates stationarity of the time series at intercept as well as intercept and trend. Therefore, gold and stock returns of all the sample countries are stationary, which fulfils the first requisite to compute the GARCH models. The ARCH LM test up to 20 lags underlines the presence of the ARCH effect in the return series. The Ljung-Box statistic up to $20^{\text {th }}$ order reveals the problem of serial autocorrelation in the return series. This meets the second requisite to proceed with GARCH models. 
Table 3. Estimation output for the hedge and safe haven assets.

\begin{tabular}{|c|c|c|c|c|c|c|c|c|}
\hline \multirow{3}{*}{ Country } & \multirow{2}{*}{\multicolumn{2}{|c|}{ Hedge }} & \multicolumn{6}{|c|}{ Safe Haven Quantiles } \\
\hline & & & \multicolumn{2}{|c|}{0.10} & \multicolumn{2}{|c|}{0.05} & \multicolumn{2}{|c|}{0.01} \\
\hline & Coeff. & P-value & Coeff. & P-value & Coeff. & P-value & Coeff. & P-value \\
\hline China & 0.0059 & 0.3429 & 0.0104 & 0.7100 & -0.0059 & 0.8577 & -0.0153 & 0.5568 \\
\hline USA & -0.0415 & $0.0007 * * *$ & 0.1050 & $0.0072^{* * *} *$ & -0.1316 & $0.0026^{* * * *}$ & 0.0078 & 0.8295 \\
\hline Australia & -0.0357 & $0.0058^{* * * *}$ & -0.0336 & 0.3381 & 0.0022 & 0.9549 & 0.0159 & 0.6488 \\
\hline Canada & -0.0026 & 0.8505 & -0.0620 & 0.1780 & 0.0044 & 0.9329 & 0.0261 & 0.5845 \\
\hline South Africa & 0.0003 & 0.9856 & 0.1400 & $0.0020^{* * * *}$ & -0.0533 & 0.3142 & -0.0946 & $0.0760^{*}$ \\
\hline
\end{tabular}

Notes: ***, ***, and * denote the statistical significance at the $1 \%, 5 \%$ and $10 \%$ levels, respectively.

Dark color shades represent a strong hedge/safe haven; light color shades represent a weak hedge/safe haven; and unshaded regions represent no hedge/safe haven cases.

Table 3 depicts the estimation results of the regression analysis shown by equations 1(a), 1(b), and 1(c). The negative coefficients in the hedge column $\left(c_{0}\right)$ denotes that gold is a hedge against stocks. The zero/negative coefficients in adverse market conditions given by quantiles $\left(10 \%\left(\mathrm{c}_{1}\right), 5 \%\left(\mathrm{c}_{2}\right)\right.$ and $1 \%\left(\mathrm{c}_{3}\right)$ shows the (weak) strong safe haven ability of gold. The hedge property is consistent across major gold producing countries with the exception of China and South Africa. Gold is a strong hedge for stock markets of the USA and Australia, and a weak hedge in Canada. However, the stock markets of China and South Africa co-move with gold on average but show negative coefficient estimates only in extreme market conditions, i.e., in the $5 \%$ and $1 \%$ quantiles of the return distributions. At very extreme equity market falls (at the $1 \%$ quantile), gold is a strong safe haven for equity market investment in South Africa and a weak safe haven in China. The pattern is similar at 5\% quantiles with the exception of the USA, where gold exhibits strong safe haven property. Adding the severity of shock, which brings a decline in stock prices, rarely matters when capturing the demand for safe haven assets. Gold shows safe haven properties in the same number of countries as the decline in stock prices deepens. For instance, at the $10 \%, 5 \%$, and $1 \%$ quantiles, countries' equity returns are negatively correlated with gold returns.

Table 4. Estimation outputs for the hedge and safe haven assets in times of crisis

\begin{tabular}{|c|c|c|c|c|c|c|c|c|c|c|}
\hline \multirow[t]{2}{*}{ Country } & \multicolumn{2}{|c|}{ Hedge } & \multicolumn{2}{|c|}{$\begin{array}{c}\text { Dot-com Bubble } \\
\text { Burst }\end{array}$} & \multicolumn{2}{|c|}{$\begin{array}{c}\text { Global Financial } \\
\text { Crisis }\end{array}$} & \multicolumn{2}{|c|}{$\begin{array}{c}\text { European Debt } \\
\text { Crisis }\end{array}$} & \multicolumn{2}{|c|}{ Covid-19 Crisis } \\
\hline & Coeff. & P-value & Coeff. & P-value & Coeff. & P-value & Coeff. & $\mathrm{P}$-value & Coeff. & P-value \\
\hline China & 0.0010 & 0.8669 & 0.0309 & 0.3773 & 0.0230 & 0.3159 & 0.0626 & $0.0290^{*} *$ & -0.0810 & 0.2773 \\
\hline USA & -0.0420 & 0.0011 **** & -0.0127 & 0.6549 & -0.0357 & 0.2714 & 0.1071 & $0.0006 * * * *$ & 0.0477 & 0.2153 \\
\hline Australia & -0.0222 & $0.0518^{*}$ & -0.0015 & 0.9668 & -0.1844 & $0.0000^{*} * * *$ & -0.1888 & $0.0000^{* * * *}$ & 0.1371 & 0.1658 \\
\hline Canada & -0.0158 & 0.3360 & -0.0310 & 0.2507 & 0.0277 & 0.4458 & 0.0058 & 0.8972 & 0.1018 & 0.0054 **** \\
\hline $\begin{array}{l}\text { South } \\
\text { Africa }\end{array}$ & 0.0794 & $0.0000 * * *$ & -0.0799 & 0.0547 * & -0.2008 & $0.0000^{* * * *}$ & -0.2108 & $0.0000^{* * * *}$ & -0.0348 & 0.4653 \\
\hline
\end{tabular}

Notes: ***, **, and *, denote the statistical significance at $1 \%, 5 \%$ and $10 \%$ levels, respectively.

Dark color shades represent a strong hedge/safe haven; light color shades represent a weak hedge/safe haven; and unshaded regions represent no hedge/safe haven cases.

Table 4 presents the safe haven properties of gold during periods of financial distress (dot-com bubble burst, global financial crisis, European debt crisis, and Covid-19 crisis). The negative coefficients in the hedge column ( $\left.\mathrm{c}_{0}\right)$ signifies that the gold is a hedge against the stock market. Negative coefficients in the subsequent columns show that it is a safe haven during the dot-com bubble burst $\left(\mathrm{c}_{1}\right)$, global financial crisis $\left(\mathrm{c}_{2}\right)$, European debt crisis $\left(\mathrm{c}_{3}\right)$, and Covid-19 crisis $\left(\mathrm{c}_{4}\right)$. The coefficient estimates for the dot-com bubble burst is negative and statistically significant, which implies that gold is a strong safe haven only for South African stock markets, but it is a weak safe haven in the USA, Canada, and Australia. The results during the global financial crisis are more heterogeneous and exhibit a larger effect in comparison with other selected crises. A substantial influence of gold as a safe haven asset was seen for almost all countries with the exception of Canada during the global financial crisis.

During the European debt crisis, the correlation among the assets decreased significantly. The estimated coefficients are positive and statistically significant for most of the countries. Moreover, the coefficients are negative 
and statistically significant only in two countries, i.e., Australia and South Africa. This gives clear evidence of the strong safe haven role of gold only in these two countries. The positive values for the remaining countries are not surprising given that these countries have not reacted to this crisis. Finally, the analysis of the recent Covid-19 crisis period shows that investors preferred gold as a safe haven asset to protect their wealth only in the cases of China and South Africa.

\subsection{Wavelet Squared Coherence}

To verify the robustness of the previous analysis outcome, the wavelet coherence approach was employed, which measures varying dependence for a bivariate series over time and across investment horizons. The results are conveyed in Figure 1.

1(a): Wavelet Squared Coherence (China)

2001 Wavelet Coherence: Gold and Stock (China)

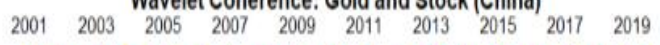

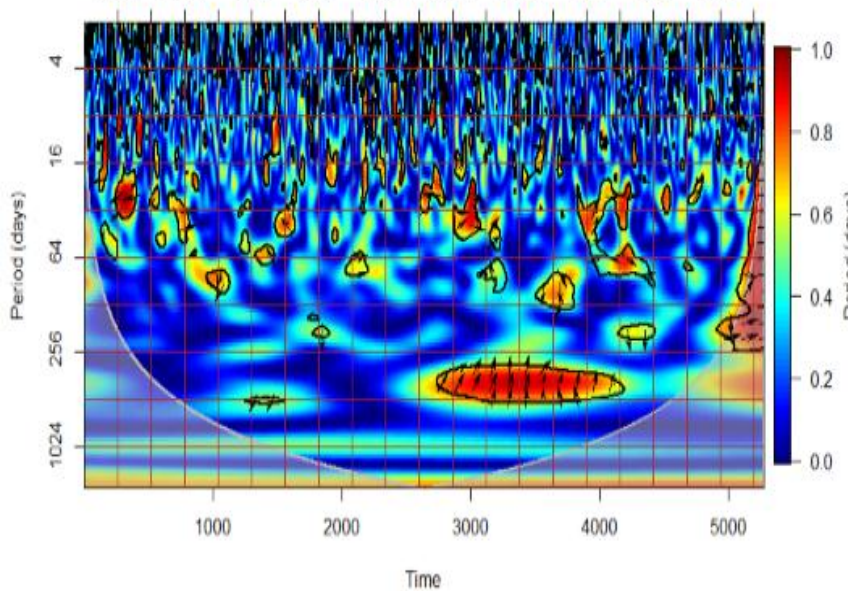

1(c): Wavelet Squared Coherence (Australia)
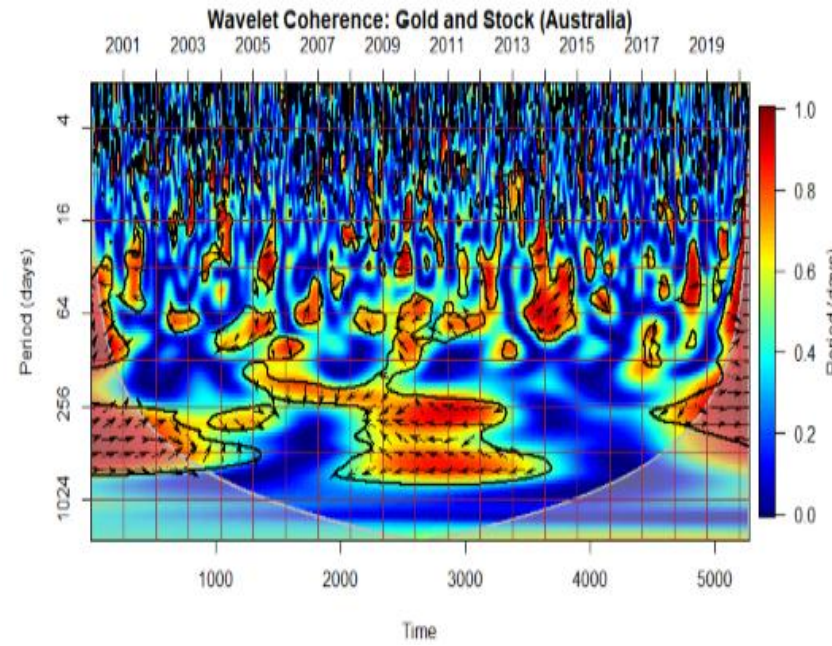

1(b): Wavelet Squared Coherence (USA)

20012003 Wavelet Coherence: Gold and Stock (US)

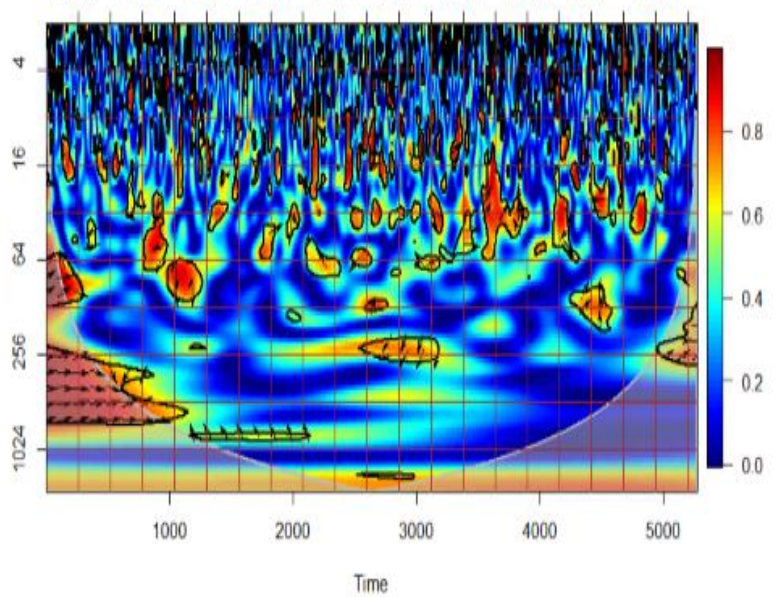

1(d): Wavelet Squared Coherence (Canada)

Wavelet Coherence: Gold and Stock (Canada)

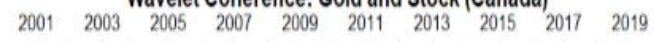

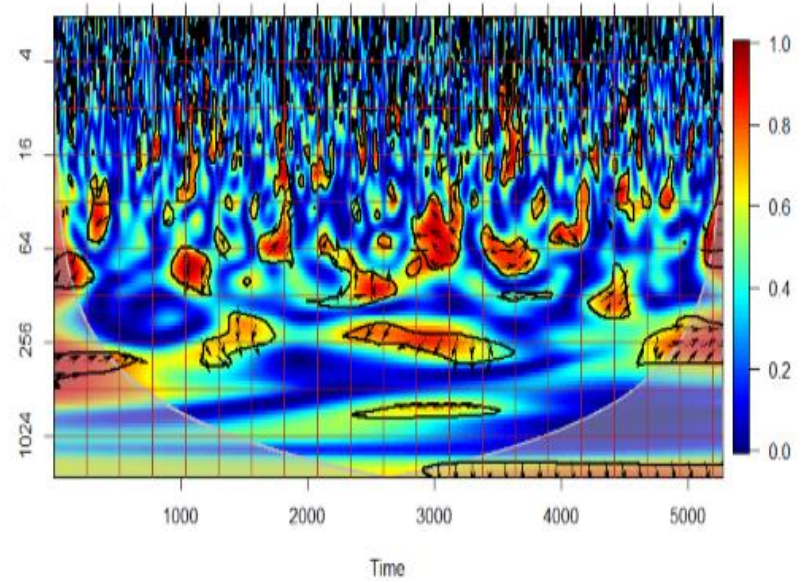




\section{1(e): Wavelet Squared Coherence (South Africa)}

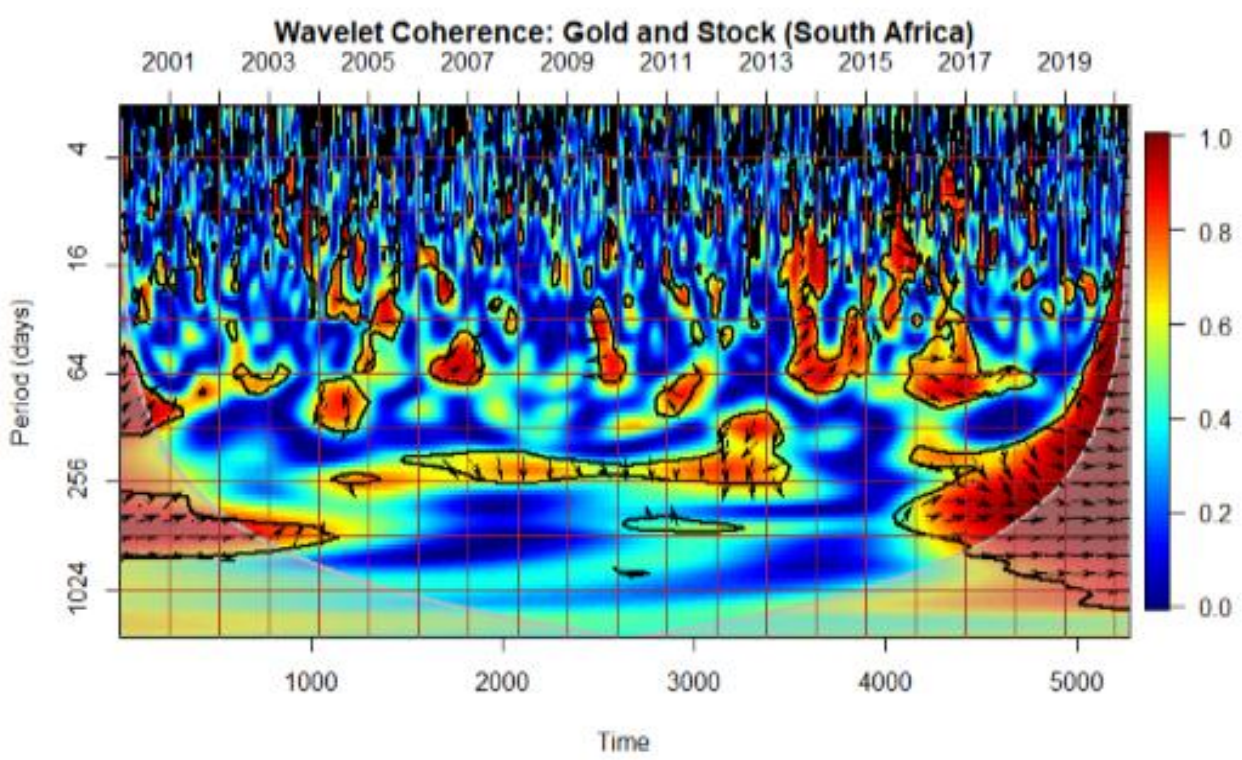

Figure 1. Wavelet Squared Coherence (WTC) Plots.

Note: Wavelet coherence is shown between gold and stock markets for a time span ranging from January 2000 to March 2020. The horizontal and vertical axes represent time dimension and frequency (in days), respectively. The area within the black contours indicates coherence that is significant at a $5 \%$ level of significance, estimated with Monte Carlo simulations. The COI indicates the region affected by edge effects and is represented by the area outside the cone in a light shade. Coherence takes values between 0 and 1, and warmer colors (deep red) are indicative of high coherence/perfect correlation, while colder colors (deep blue) are indicative of low coherence/no correlation. The phase difference between the two series is indicated by arrows. East (west) facing arrows show the in (out of) phase, while north (south) facing arrows show that gold leads (lags) the traditional asset. A north-east (south-east) facing arrow symbolizes that the series are in-phase but that gold (traditional asset) leads the traditional asset (gold). In phase, the variables have a positive correlation, and out of phase, or anti-phase, shows a negative correlation.

Figure 1(a) reports the wavelet coherence between gold and the China stock index. Overall, the predominance of the color blue shows very low co-dependency between gold and the stock over time as well as the selected period. In the case of Chinese stock, low coherency dominates at short horizons as well as long horizons on average. This suggests that gold acts as both a short- and long-horizon hedge. Up to a period of 32 days, very little evidence of coherence exists with left facing arrows indicating a weak safe haven property of gold during 2001, which is marked by the dot-com bubble burst. Beyond this horizon, distinct pockets of coherence are found. In the case of equities, north-east facing arrows from 2010 to 2016 at a higher frequency horizon (greater than 256 days) indicates that the series is in phase with gold leading equities.

In the wavelet coherence plot of the USA, at shorter periods of around eight days, there were very limited bands of high coherence (red color) visible between gold and equities. During the time span from 2001 to 2002 , at periods of approximately 64 days, a small patch of red with westward-facing arrows represents the negative dependency between gold and US stocks. This signifies the weak safe haven ability of gold during the dot-com bubble burst. A further increased negative coherence was experienced over 1024 days (longer horizons) in 20072008 with north-west facing arrows corresponding to the phase of the global financial crisis.

Figure 1(c) exhibits the wavelet coherence between gold and Australian equity markets. Initially, during the dotcom bubble burst negligible short-horizon coherence with arrows in the left direction demonstrates the weak safe haven property of gold. Moreover, at longer horizons, there is strong evidence of positive coherence among the assets. The analysis of the global financial crisis has shown negative long horizon coherence, usually linked with a safe haven. An extended band of high coherency both at medium- and long-term horizons exhibited during European debt crisis. This suggests that including the yellow asset in a portfolio would have aided in decreasing the portfolio risk during this turmoil. Surprisingly, the safe haven status of gold was not displayed during the recent Covid crisis. Gold exhibits comparatively strong hedge and safe haven properties across all crises, except the Covid19 crisis in Australian stock markets, with a more pronounced effect during the European debt crisis across all investment horizons. This implies that gold does not glitter for all types of crises. 
In the case of Canada, evidence of hedge was exhibited up to a short horizon of 8 days throughout the sample period. During later phases, a large number of red droplets were found with arrows in the phase facing east. A high positive co-dependence among markets was seen wherein the gold market was leading stock markets. However, during the internet bubble burst in 2001, a small red patch with westward-facing arrows gives conclusive evidence of the weak safe haven ability of gold.

Finally, Figure 1(e) depicts the coherence between gold and South African equities. A close look at the plot reveals a high degree of co-movement and synchronization with highly concentrated red regions at the various frequency bands over a time span from 2001 to 2020. This high co-movement between gold and stocks is particularly associated with the high dependence of the South African economy on its natural resources, namely gold. The safe haven property is displayed across all the crisis periods, and specifically, during such turmoil, an equity investor would have avoided a huge loss by holding a portfolio in a combination of gold.

\section{CONCLUSION}

This paper addresses the hypothesis of whether gold serves as a hedge or a haven asset against the stock market downturns in major gold producing countries. A range of methodological framework is adopted beginning with the methodology by Baur \& McDermott (2010). Accordingly, the severity of shocks was captured by considering the lowest quantiles of the return distribution. The results revealed that the severity of shock which brings a decline in stock prices rarely matters when capturing the demand for safe haven assets. Across all quantiles, gold shows to be a safe haven in the same number of countries. Even at extreme quantiles of $1 \%$, investors in South Africa and China still prefer gold as a weak haven asset.

Furthermore, a comparative analysis during crises evidenced a more heterogeneous and larger effect during the internet bubble burst in 2001 in comparison with other selected crises. Finally, a robustness analysis was carried out through wavelet coherence to get a better picture across different crises and from the perspective of multihorizon investors. The findings demonstrated a predominance of red bounds and westward-facing arrows indicating the strong safe haven effect of gold during most of the crisis periods in the case of Australia and South Africa. This can be on account of an increasing trend of gold prices marked with the financialization of commodities in 2002 and the rising preference of investors for gold as a safe haven asset in the aftermath of successive financial turmoils. Gold does not serve as a stabilizing force to reduce losses in times of financial distress in the case of Chinese equity markets, as it was the least affected financial market during all the crises. However, Chinese stock markets quickly responded to the recent Covid-19 pandemic and investors preferred gold as a refuge asset to protect their risk exposure in the initial phases. This is because Covid-19, a deadly and contagious disease, initially originated in China and its effect was first experienced in China at its outbreak and thereafter spread across the rest of the world.

Funding: This study received no specific financial support.

Competing Interests: The authors declare that they have no competing interests

Acknowledgement: Both authors contributed equally to the conception and design of the study.

\section{REFERENCES}

Baur, D. G., \& McDermott, T. K. (2010). Is gold a safe haven? International evidence. Journal of Banking E̊ Finance, 34(8), 18861898. Available at: https://doi.org/10.1016/j.jbankfin.2009.12.008.

Baur, D. G., \& Lucey, B. M. (2010). Is gold a hedge or a safe haven? An analysis of stocks, bonds and gold. The Financial Review, 45(2), 2 17-229. Available at: https://doi.org/10.1111/j.1540-6288.2010.00244.x.

Beckmann, J., Berger, T., \& Czudaj, R. (2015). Does gold act as a hedge or a safe haven for stocks? A smooth transition approach. Economic Modelling, 48, 16-24. Available at: https://doi.org/10.1016/j.econmod.2014.10.044. 
Bekiros, S., Boubaker, S., Uddin, G. S., \& Nguyen, D. K. (2017). Black swan events and safe havens: The role of gold in globally integrated emerging markets. Journal of International Money and Finance, 73, 317-334. Available at: https://doi.org/10.1016/j.jimonfin.2017.02.010

Bhanja, N., \& Dar, A. B. (2015). The beauty of gold is, it loves bad news: Evidence from three major gold consumers. Economic Change and Restructuring, 48(3-4), 187-208. Available at: 10.1007/s 10644-015-9160-z.

Bredin, D., Conlon, T., \& Potì, V. (2015). Does gold glitter in the long-run? Gold as a hedge and safe haven across time and investment horizon. International Review of Financial Analysis, 41, 320-328. Available at: https://doi.org/10.1016/j.irfa.2015.01.010.

Chkili, W. (2016). Dynamic correlations and hedging effectiveness between gold and stock markets: Evidence for BRICS countries. Research in International Business and Finance, 38, 22-34. Available at: https://doi.org/10.1016/j.ribaf.2016.03.005.

Dar, A. B., \& Maitra, D. (2017). Is gold a weak or strong hedge and safe haven against stocks? Robust evidences from three major gold-consuming countries. Applied Economics, 49(53), 5491-5503. Available at: https://doi.org/10.1080/00036846.2017.1310998.

Gurgun, G., \& Unalmıs, I. (2014). Is gold a safe haven against equity market investment in emerging and developing countries? Finance Research Letters, $11(4)$, 341-348. Available at: https://doi.org/10.1016/j.frl.2014.07.003.

Hood, M., \& Malik, F. (2013). Is gold the best hedge and a safe haven under changing stock market volatility? Review of Financial Economics, 22(2), 47-52. Available at: https://doi.org/10.1016/j.rfe.2013.03.001.

Kaul, A., \& Sapp, S. (2006). Y2K fears and safe haven trading of the U.S. dollar. Journal of International Money and Finance, 25(5), 760-779. Available at: https://doi.org/10.1016/j.jimonfin.2006.04.003.

Lucey, B. M., \& Li, S. (2015). What precious metals act as safe havens, and when? Some US evidence. Applied Economics Letters, 22(1), 35-45. Available at: https://doi.org/10.1080/13504851.2014.920471.

McCown, J. J., \& Zimmerman, J. R. (2006). Is gold a zero-beta asset? Analysis of the investment potential of precious metals. Available at: http://dx.doi.org/10.2139/ssrn.920496.

Torrence, C., \& Compo, G. P. (1998). A practical guide to wavelet analysis. Bulletin of the American Meteorological Society, 79(1), 61-78. Available at: https://doi.org/10.1175/1520-0477(1998)079<0061:APGTWA>2.0.CO;2. 